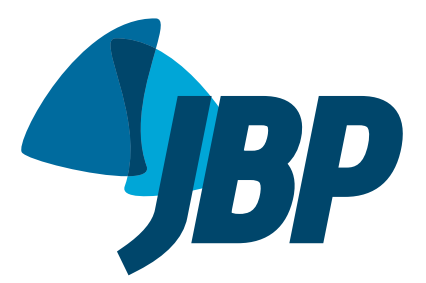

1. Institute for Pulmonary Diseases of Vojvodina, Sremska Kamenica, Republic of Serbia.

2. Medical Faculty Novi Sad, University of Novi Sad, Novi Sad, Republic of Serbia.

3. General Hospital Sremska Mitrovica, Sremska Mitrovica, Republic of Serbia.

Submitted: 26 January 2017.

Accepted: 14 April 2017.

Study carried out at the Institute for Pulmonary Diseases of Vojvodina,

Sremska Kamenica, Republic of Serbia.

\section{Frequency of COPD in health care workers who smoke}

\author{
Ivan Kopitovic ${ }^{1,2}$, Aleksandar Bokan ${ }^{1,2}$, Ilija Andrijevic ${ }^{1,2}$, Miroslav Ilic ${ }^{1,2}$, \\ Sanja Marinkovic ${ }^{3}$, Dragana Milicic ${ }^{1,2}$, Marija Vukoja $^{1,2}$
}

\begin{abstract}
Objective: COPD is one of the major causes of morbidity and mortality worldwide. Health care providers should counsel their smoking patients with COPD to quit smoking as the first treatment step. However, in countries with high prevalences of smoking, health care workers may also be smokers. The aim of this study was to determine the frequency and severity of COPD in health care workers who smoke. Methods: This was a cross-sectional study. All health care workers who smoke, from nine health care centers in Serbia, were invited to participate in the study and perform spirometry. The diagnosis of COPD was based on a post-bronchodilator $\mathrm{FEV}_{1} / \mathrm{FVC}$ ratio of $<0.70$. All patients completed the COPD Assessment Test and the Fagerström Test for Nicotine Dependence. Results: The study involved 305 subjects, and 47 (15.4\%) were male. The mean age of the participants was $49.0 \pm 6.5$ years. Spirometry revealed obstructive ventilatory defect in 33 subjects (10.8\%); restrictive ventilatory defect, in 5 (1.6\%); and small airway disease, in 96 (31.5\%). A diagnosis of COPD was made in 29 patients (9.5\%), 25 (86.2\%) of whom were newly diagnosed. On the basis of the Global Initiative for COPD guidelines, most COPD patients belonged to groups $A$ or $B$ ( $n=14 ; 48.2 \%$, for both); 1 belonged to group $\mathrm{D}$ (3.6\%); and none, to group $\mathrm{C}$. Very high nicotine dependence was more common in those with COPD than in those without it $(20.7 \%$ vs. $5.4 \%, p=$ 0.01). Conclusions: In this sample of health care workers, the frequency of COPD was comparable with that in the general population. The presence of COPD in health care workers who smoke was associated with higher nicotine dependence.
\end{abstract}

Keywords: Pulmonary disease, chronic obstructive/prevention \& control; Smoking; Health personnel.

\section{INTRODUCTION}

COPD is one of the most common chronic diseases in adults and a major cause of chronic morbidity and mortality throughout the world. According to the World Health Organization, more than 210 million people suffer from COPD at a global level, and 80 million present its moderate-to-severe form. ${ }^{(1)}$ In the period between 1990 and 2010, there was an increase in the prevalence of COPD, from $10.7 \%$ to $11.7 \%$. (2) Population studies have estimated that the absolute number of patients with COPD will increase by $150 \%$ in the period between 2010 and 2030, the largest increase being in people over 75 years of age. ${ }^{(3)}$

In 2005, more than 3 million people died of COPD, which corresponds to $5 \%$ of all adult deaths globally. ${ }^{(4)}$ A study regarding the global burden of COPD, which was the fourth leading cause of death in 1990 and the third leading cause of death in 2010,(5) projected that the disease will remain the third leading cause of death worldwide by 2020. Despite the significant burden of COPD on health and quality of life, the disease is often unrecognized and undertreated because the most common symptoms, such as fatigue and dyspnea on exertion, are commonly perceived as normal for the aging population. Recent data show that smokers who do not have COPD often have COPD symptoms and express common COPD features, such as exacerbations and activity limitation, and almost half of those use bronchodilators. ${ }^{(6)}$ Symptomatic smokers and those who are at early COPD stages are most likely to benefit from early treatment strategies, such as smoking cessation.

Even though tobacco smoking is the major preventable risk factor associated with the development of COPD, (7) according to two national studies in the USA, ${ }^{(8)}$ only $20.9 \%$ of current tobacco users have received physician counseling on tobacco cessation. Moreover, studies suggest that the number of health care workers who smoke is high, especially in countries with high prevalences of smokers. ${ }^{(9)}$

The primary aim of the present study was to determine the frequency and severity of COPD in health care workers who smoke. The secondary aim was to determine the occurrence of respiratory symptoms, abnormal patterns in their lung function, and the influence of the level of nicotine dependence on the development of COPD in health care workers.

Correspondence to:

Ivan Kopitovic. Institute for Pulmonary Diseases of Vojvodina, Put doktora Goldmana 4, 21204, Sremska Kamenica, Republic of Serbia.

Tel./Fax: 381214805175. E-mail: ikopitovic@gmail.com or ivan.kopitovic@mf.uns.ac.rs

Financial support: This study received financial support from the Provincial Secretariat for Science and Technological Development, Autonomous Province of

Vojvodina, Republic of Serbia (Project no. 114-451-718/2015-02) 


\section{METHODS}

\section{Study design and population}

The study was designed as a cross-sectional study including adult health care workers who smoke to form a convenience sample. It was conducted in the period between August 1, 2015 and August 1, 2016, and the participants were selected from nine medical institutions in Vojvodina, Serbia. Vojvodina is a northern province of Serbia, with an estimated 1.9 million population, which comprise $21.56 \%$ of the total population in Serbia. The nine medical centers had a total of 5,635 medical workers, 4,318 (76.63\%) being female. The study included subjects $\geq 40$ years of age who were current cigarette smokers. The volunteers were invited to perform spirometry. The study was approved by the Research Ethics Committee of the Institute for Pulmonary Diseases in Sremska Kamenica, Serbia.

\section{Study variables}

We collected basic demographic data and the medical history of the subjects, including information regarding a diagnosis of COPD, asthma, and other lung diseases. Demographic data included gender, age, occupation, and smoking history (in pack-years). All participants completed a closed questionnaire on COPD symptoms and the number of respiratory infections requiring treatment with antibiotics or corticosteroids in the previous year.

The COPD Assessment Test (CAT) was used to determine the presence and severity of respiratory symptoms. If a patient had a CAT score $>0$ on a specific item, the patient was classified as having that symptom. The intensity of symptoms was measured by the total and item-specific CAT score. The Fagerström Test for Nicotine Dependence (FTND) was used for assessing nicotine dependence. Spirometry was performed according to the standards of the American Thoracic Society and European Respiratory Society. ${ }^{(10)}$

Obstructive ventilatory defect was defined as a $\mathrm{FEV}_{1} /$ FVC ratio $<0.70$ on initial spirometry. We performed the bronchodilator reversibility test in those patients with detected airway obstruction. The diagnosis of COPD was based on post-bronchodilator $\mathrm{FEV}_{1} / \mathrm{FVC}$ ratio < 0.70. Small airway disease was defined as $\mathrm{FEF}_{25-75 \% \text { ' }}$ $\mathrm{FEF}_{50 \%}$, or $\mathrm{FEF}_{75 \%}<50 \%$. (11) Restrictive ventilatory defect was defined as FVC $<80 \%$ in patients with a $\mathrm{FEV}_{1} / \mathrm{FVC}$ ratio $>70 \%$. The assessment of disease severity was based on the CAT questionnaire and the number of exacerbations that the patient had in the previous year. All patients were classified according to the 2017 Global Initiative for Chronic Obstructive Lung Disease (GOLD) guidelines for COPD severity. ${ }^{(12)}$

\section{Ethical approval}

All procedures performed in studies involving human participants were in accordance with the ethical standards of the institutions involved and the national research committee, as well as with the Helsinki declaration and its later amendments or comparable ethical standards. The study was approved by the Research Ethics Committee of the Institute for Pulmonary Diseases in Sremska Kamenica, Serbia.

\section{Statistical analysis}

Continuous variables are presented as means and standard-deviations, whereas categorical variables are presented as frequencies and proportions. We used the Student's t-test for the comparison of continuous variables, the chi-square test for the comparison of categorical variables, and ANOVA for the comparison of continuous variables across three or more categories. The level of significance was set at $5 \%(p<0.05)$ for all tests.

\section{RESULTS}

The study involved 305 health care workers (47 men and 258 women). The mean age was $49.0 \pm 6.5$ years, and the mean history of smoking was $23.0 \pm 14.2$ pack-years. The mean FTND score was $4.48 \pm 4.47$. Most of the subjects showed low nicotine dependence (28.9\%), followed by high nicotine dependence $(27.8 \%)$, very low nicotine dependence $(18.5 \%)$, moderate nicotine dependence (17.9\%) and very high nicotine dependence $(6.9 \%)$. Most of the respondents were nurses ( $n=169 ; 55.4 \%$ ). Basic demographic data are presented in Table 1 .

Respiratory symptoms were present in 186 subjects $(61.0 \%)$. The most common symptoms were "breathlessness while walking up a hill or a flight of stairs" ( $n=104 ; 34.0 \%)$; "cough" ( $n=96 ; 31.5 \%)$; "expectoration" ( $n=68 ; 22.3 \%)$; "wheezing" $(n=46$; $15.0 \%)$; "shortness of breath" $(n=40 ; 13.1 \%)$; "chest tightness" ( $n=7 ; 2.3 \%)$; and "impaired sleep due to breathing problems" ( $n=6 ; 2.0 \%$ ). Breathing problems disrupted daily physical activity in 14 subjects (4.6\%). The mean CAT score was $7.69 \pm 7.10$. Respiratory infection requiring the use of antibiotics in previous year was present in 57 subjects (18.7\%).

Regarding COPD, 16 subjects (5.2\%) had been previously diagnosed with the disease. Chronic extrapulmonary diseases were present in 54 subjects $(17.7 \%)$, hypertension being the most common disease $(11.0 \%)$.

Spirometry confirmed obstructive ventilatory defect in 33 subjects $(10.8 \%)$, restrictive ventilatory defect, in 5 $(1.6 \%)$, and small airway disease, in $96(31.5 \%)$. There was no statistically significant difference between the subjects with and without airway obstruction regarding gender. Patients with airway obstruction were older and heavier smokers. Very high nicotine dependence was more common in patients with airflow obstruction (18.2\% vs. $5.6 \% ; p=0.016$ ).

A diagnosis of COPD was made in 29 subjects (9.5\%), 4 of whom had been previously diagnosed with COPD, whereas 25 (86.2\%) were newly diagnosed patients. On the basis of the GOLD spirometric classification, most of the subjects with COPD were in stage I $(n=20$; $68.9 \%$ ), followed by those in stage II ( $n=8 ; 27.6 \%$ ). Only 1 subject was in stage III, having previously 
been diagnosed with COPD. On the basis of the GOLD classification based on symptoms and risk, the majority of respondents were in group $A(n=14 ; 48.2 \%)$ or $B$ $(n=14 ; 48.2 \%)$. One subject $(3.6 \%)$ had a severe form of COPD and belonged to group D. None of the subjects belonged to group $\mathrm{C}$. There were no significant differences between patients with and without COPD in relation to occupation, gender, and body mass index; however, there was a significant difference between those subjects in relation to age, smoking history, and level of nicotine dependence (Table 2). There was no association between occupation (physicians, nurses, and allied health professionals) and level of nicotine dependence (mean FTND score, $4.26 \pm 2.36$ vs. 4.51

Table 1. Characteristics of the study population $(\mathrm{N}=305) \mathrm{r}^{\mathrm{a}}$

\begin{tabular}{lc} 
Male & Result \\
Female & $47(15.4)$ \\
Age, years & $258(84.6)$ \\
Smoking history, years & $49.0 \pm 6.5$ \\
Smoking history, pack-years & $25.0 \pm 8.4$ \\
Nicotine dependence, FTND score & $23.0 \pm 14.2$ \\
$\quad$ Very low, 0-2 & \\
$\quad$ Low, 3-4 & $56(18.5)$ \\
$\quad$ Moderate, 5 & $88(28.8)$ \\
High, 6-7 & $55(17.9)$ \\
Very high, 8-10 & $85(27.8)$ \\
Occupation, $n$ (\%) & $21(6.9)$ \\
Doctors and pharmacists & \\
Nurses & $54(17.7)$ \\
Allied health care professionals & $169(55.4)$ \\
\hline
\end{tabular}

FTND: Fagerström Test for Nicotine Dependence.

avalues expressed as $\mathrm{n}(\%)$ or mean $\pm \mathrm{SD}$. \pm 2.17 vs. $4.54 \pm 2.15$, respectively; $p=0.72$ ). The subjects with higher levels of nicotine dependence had a higher burden of respiratory symptoms (a mean CAT score of $6.10 \pm 5.95$ and an FTND score of 0-4 vs. a mean CAT score of $7.83 \pm 7.24$ and an FTND score of 5-7 vs. a mean CAT score of $9.78 \pm 8.10$ and an FTND score of $8-10 ; p<0.001)$. In subjects with no diagnosis of COPD, the presence of other spirometric defects was not associated with higher CAT scores (mean CAT score, $7.80 \pm 6.42$ in subjects with a restrictive pattern vs. $5.70 \pm 7.37$ in subjects with an obstructive pattern vs. $8.41 \pm 7.94$ in subjects with small airway obstruction vs. $7.14 \pm 6.81$ in subjects with normal spirometry; $p=0.66$ ).

Impaired sleep due to breathing problems and chest tightness were significantly more common in subjects with COPD than in those without the disease. Although cough, expectoration, and shortness of breath were found to be more common in subjects with COPD than in those without it, the differences were not statistically significant (Figure 1).

The intensity of cough and shortness of breath, as measured by the CAT score, was significantly higher in subjects with COPD than in those without the disease $(1.9 \pm 1.3$ vs. $1.2 \pm 1.2 ; p=0.004 ;$ and $2.2 \pm 1.7$ vs. $1.5 \pm 1.5 ; p=0.03$ ).

There was no difference in the frequency of respiratory infections requiring antibiotic treatment in the previous year between subjects with and without COPD $(20.69 \%$ vs. $18.48 \% ; p=0.77$ ).

\section{DISCUSSION}

The present study has provides an insight into the health of health care workers when it comes to COPD,

Table 2. Characteristics of the subjects with and without COPD $(\mathrm{N}=305){ }^{\text {a }}$

\begin{tabular}{|c|c|c|c|}
\hline \multirow[t]{2}{*}{ Characteristic } & \multicolumn{2}{|c|}{ COPD } & \multirow[t]{2}{*}{ p } \\
\hline & Yes & No & \\
\hline Male, \% & 17.0 & 83.0 & 0.09 \\
\hline Female, \% & 8.1 & 91.9 & \\
\hline Age, years & $53.7 \pm 5.1$ & $48.7 \pm 6.0$ & $<0.001$ \\
\hline Smoking history, years & $29.5 \pm 8.3$ & $24.5 \pm 8.2$ & 0.004 \\
\hline Smoking history, pack-years & $32.5 \pm 17.7$ & $22.8 \pm 13.5$ & 0.001 \\
\hline Very high nicotine dependence, $\%$ & 20.7 & 5.4 & 0.013 \\
\hline $\mathrm{BMI}, \mathrm{kg} / \mathrm{m}^{2}$ & $26.6 \pm 4.9$ & $25.9 \pm 6.3$ & 0.57 \\
\hline Occupation & & & 0.71 \\
\hline Doctors and pharmacists & $48(88.9)$ & $6(11.1)$ & \\
\hline Nurses & $152(90.0)$ & $17(10.0)$ & \\
\hline Allied health care professionals & $76(92.7)$ & $6(7.3)$ & \\
\hline \multicolumn{4}{|l|}{ Spirometry } \\
\hline $\mathrm{FEV}_{1}, \%$ of predicted & $84.4 \pm 22.6$ & $101.7 \pm 15.7$ & $<0.001$ \\
\hline FVC, $\%$ of predicted & $105.9 \pm 15.8$ & $109.4 \pm 15.3$ & 0.24 \\
\hline $\mathrm{FEV}_{1} / \mathrm{FVC}$ ratio, $\%$ & $64.0 \pm 4.0$ & $79.0 \pm 0.1$ & $<0.001$ \\
\hline PEF, \% of predicted & $81.9 \pm 21.6$ & $98.2 \pm 20.3$ & $<0.001$ \\
\hline $\mathrm{FEF}_{50 \%}, \%$ of predicted & $40.5 \pm 12.2$ & $82.3 \pm 24.6$ & $<0.001$ \\
\hline $\mathrm{FEF}_{75 \%}, \%$ of predicted & $44.2 \pm 21.3$ & $75.2 \pm 29.4$ & $<0.001$ \\
\hline $\mathrm{FEF}_{25-75 \%}, \%$ of predicted & $39.2 \pm 13.0$ & $80.4 \pm 26.3$ & $<0.001$ \\
\hline
\end{tabular}

BMI: body mass index. ${ }^{a}$ Values expressed as $\mathrm{n}(\%)$ or mean \pm SD, except where otherwise indicated. 
the most common lung disease in the world. We found an incidence of COPD of $9.5 \%$ in our sample of health care workers who smoke. The vast majority of the COPD cases in our sample of health care workers were newly diagnosed (86.2\%).

The prevalence of COPD in the general population ranges from $0.2 \%$ to $18.3 \%$. In Europe, it is estimated to range from $4 \%$ to $10 \%,{ }^{(13)}$ whereas the incidence of newly diagnosed cases of COPD in high-risk populations varies from $10.9 \%$ to $29.5 \%,^{(14-17)}$ depending on the geographic location, the structure of the study population, and the scope of previous screening for COPD. The major reason for a late diagnosis of COPD is that the majority of patients with decreased FEV $_{1}$ do not complain of any respiratory symptoms. The slow, progressive nature of COPD appears to lead to a reduced awareness of the signs of the disease. For example, a smoker coughing every morning is often perceived as a normal phenomenon. ${ }^{(18)}$

Results of the present study demonstrate that $61 \%$ of the health care workers who smoke have respiratory symptoms, the most common being breathless while walking up a hill or one flight of stairs (34.0\%), cough $(31.5 \%)$, sputum expectoration $(22.3 \%)$, and wheezing $(15.0 \%)$. Similar results were found in a recent five-year study involving 1,812 smokers and former smokers, in which $50 \%$ of the participants had respiratory symptoms, despite having preserved pulmonary function, which was significantly more common than in nonsmokers (16\%). ${ }^{(6)}$ Although there were no significant differences regarding the frequency of cough and of shortness of breath between the subjects with and without COPD, the intensity of these symptoms was more pronounced in those with COPD. Subjects with COPD had sleep disruption and chest tightness more commonly than did smokers without COPD, suggesting that these complaints might be more specific in the smoking population with COPD. These results are in line with the those found in a study by Regan et al., who showed that respiratory symptoms, limitation of daily activities, and abnormalities on CT scans of the chest are often present in smokers who do not manifest airway obstruction on spirometry. ${ }^{(19)}$ This suggests that clinical COPD, which includes chronic cough, dyspnea, and chronic sputum production, together with a history of exposure to risk factors, is often present in smokers and that it is likely that this group of patients would largely benefit from early prevention strategies, such as smoking cessation. Despite the high burden of symptoms in health care workers, they were unaware of the possibility of having COPD, as evidenced by the fact that most of the COPD cases had not been previously diagnosed. In addition, most of the COPD cases were heavy smokers. This is of utmost importance because health care workers play a major role in counseling their patients on the importance of smoking cessation and have the responsibility to deliver nonpharmacological interventions in the treatment of their COPD patients. In addition, the benefit of smoking cessation spreads far beyond the treatment of COPD. Importantly, none of the centers involved in the present study had an established smoking prevention program.

On spirometry, obstructive ventilatory defect was confirmed in 33 participants $(10.8 \%)$; restrictive ventilatory defect, in 5 (1.6\%); and small airway disease, in $96(31.5 \%)$. On the basis of the GOLD classification, the majority of the respondents with COPD were in groups A or B ( $n=14 ; 48.2 \%$, for both), and only 1 patient $(3.6 \%)$ was in group D. Since we performed screening in a high-risk population in our study, most of the COPD patients were newly diagnosed and in the early stages of the disease. This is very important because most patients with COPD are diagnosed in the third or fourth stage of the disease, when the respiratory reserve is reduced by more than $50 \%$, and the largest

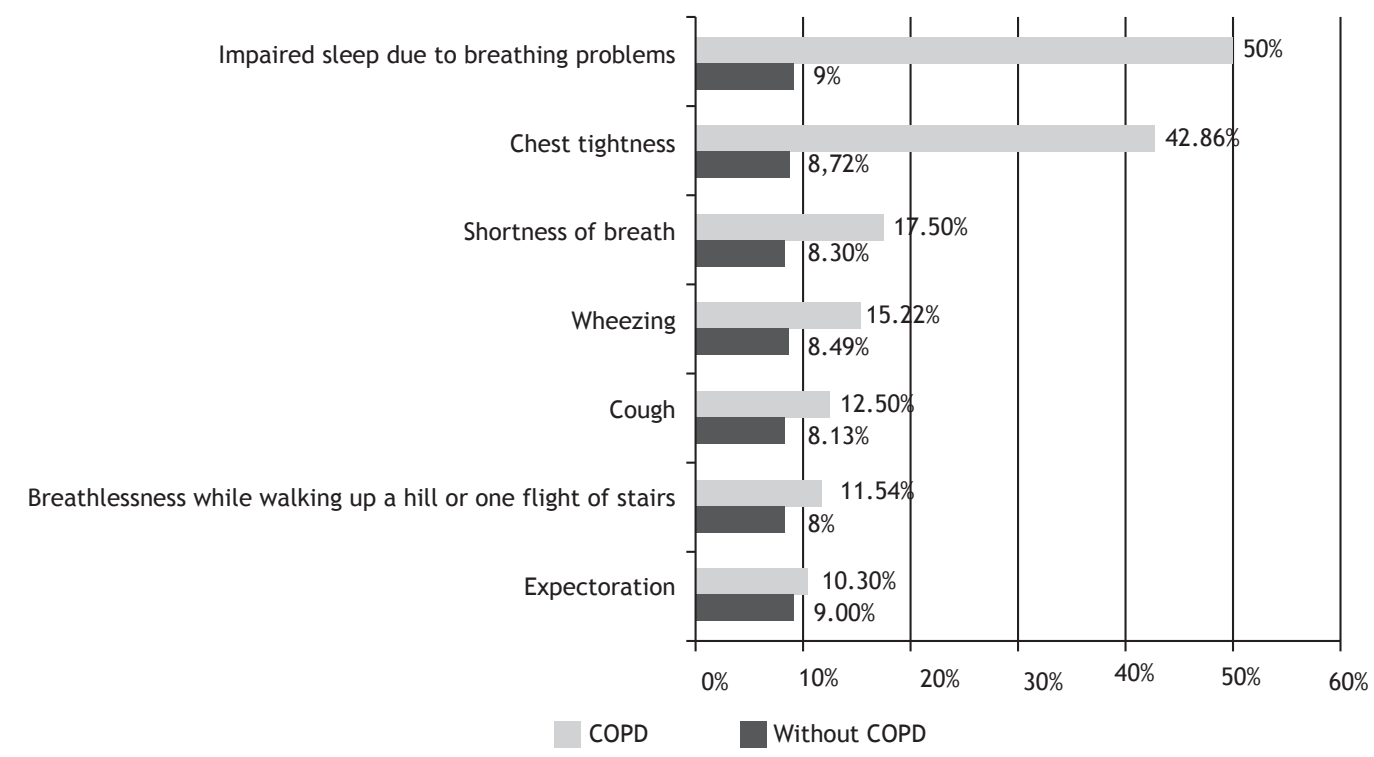

Figure 1. Frequency of respiratory symptoms in patients with and without COPD. 
decline in lung function occurs in the first and second stages of the disease. ${ }^{(20)}$ Timely diagnosis and treatment reduce health and socioeconomic consequences for the individual and society. In the USA, the results of a follow-up study based on the First National Health and Nutrition Examination Survey showed that the risk of mortality was $1.3,1.7$, and 3.1, respectively, in patients in GOLD COPD stage I, stage II, and stages III-IV. ${ }^{(21)}$ In addition, the five-year mortality rate depends on the stage of the disease, ranging from $17 \%$ in stage I patients to $73 \%$ in stage IV patients. ${ }^{(22)}$

The frequency of COPD is primarily the result of cumulative exposure to different risk factors for many decades. The prevalence of COPD is often directly related to the frequency of tobacco use and level of air pollution. A meta-analysis of studies conducted in 28 countries between 1990 and 2004 and a study in Japan provide evidence that the prevalence of COPD is significantly higher in smokers and former smokers than in nonsmokers, in those older than 40 years of age than in those younger than 40 years of age, and in men than in women. ${ }^{(23,24)}$ From 1965 to 2012 , the prevalence of cigarette smoking in the USA decreased from $42.4 \%$ to $18.1 \%$. ${ }^{(25)}$ According to data from 2013 , it is estimated that $34.7 \%$ of the population of Serbia are smokers, with the highest proportion of smokers in the 18-64 year age group, i.e., the working population. Despite recent law regulations that restrict smoking in Serbia, there have been no changes in the number of smokers since 2006. (26) In our study, the participants with COPD were older and had a longer smoking history (in pack-years) when compared with the participants without COPD. These results are expected, since age and smoking history are two dominant risk factors for the development of COPD. ${ }^{(27)}$ In general, COPD is more prevalent in males. $(28,29)$ However, in our study, most of the subjects were female, and the results of our study could be related to the occupation of the subjects. The majority of the respondents were nurses, and there is a possibility that they were more interested in having their health status investigated than were doctors. In addition, most health care workers in the participating centers were female $(77 \%)$. The results of our study also showed a statistically significant association between smoking history (pack-years) and a diagnosis of COPD. Respondents with very high nicotine dependence were significantly more commonly diagnosed with COPD. This is in line with previous studies that showed that, for each point increase in the FTND score, the probability of a smoker developing COPD increases by $11 \%$.(30)

Our study has several limitations. First, the study included a selected group of health care workers who volunteered to participate in the study, and they are not necessarily representative of all health care workers who smoke. Second, since we included only current smokers, the prevalence of COPD in health care workers might be higher. However, we were specifically interested in health care workers who continue to smoke, who present with the obvious health-related risks. Third, we acknowledge the well-known limitation of using a fixed spirometric value for determining obstruction, which can cause the overdiagnosis of the disease in the elderly and its underdiagnosis in younger patients. However, current COPD guidelines favor the use of this threshold due to its consistency, simplicity, and limited risk of misdiagnosis. ${ }^{(12)}$ Fourth, although we reported the spirometric indices of small airway disease, these are highly variable and nonspecific, and therefore are not generally recommended. ${ }^{(31)}$ Finally, the present study is prone to recall bias with regard to the number of exacerbations in the previous year, which is often inaccurately reported in COPD patients. ${ }^{(32)}$ Despite these limitations, to our knowledge, this is the first contemporary study that explores the occurrence of respiratory symptoms and COPD in health care workers who smoke. The study is strengthened by the use of spirometry to make a diagnosis of COPD and by the standardized approach of measuring symptoms and grading COPD severity. We believe that our study is important because it provides an insight on the smoking impact in a country with a high prevalence of smokers. In such countries, the detrimental effects of smoking-related diseases are likely to be seen in upcoming years in contrast to those where there has been a significant reduction in the prevalence of smoking. Needless to say, the role of health care workers in such settings is of paramount importance, and the present study highlights the need for education and prevention programs in this population.

In conclusion, we showed that the frequency of COPD in health care workers is comparable to that in the general population and that it is associated with higher nicotine dependence. Despite being symptomatic, health care workers were unaware of the possibility that they might have COPD, as evidenced by the fact that most of the COPD cases were newly diagnosed. The present study demonstrates the necessity of educational programs for COPD prevention and of early treatment among health care workers.

\section{ACKNOWLEDGMENTS}

We would like to thank the following institutions: Clinical Centre of Vojvodina in Novi Sad; Institute of Occupational Health "Zeleznice Srbije" in Novi Sad; Dispensary for Pulmonary Diseases and Tuberculosis in Subotica; General Hospital in Sremska Mitrovica; General Hospital "Dr Radivoj Simonovic" in Sombor; General Hospital "Djordje Joanovic" in Zrenjanin; Special Hospital for Pulmonary Disease "Dr Vasa Savic" in Zrenjanin; and Community Health Center in Zabalj.

\section{REFERENCES}

1. CruzAA, Bousquet J, Khaltaev NG, editors. Global surveillance, prevention and control of chronic respiratory diseases: a comprehensive approach 
2. Adeloye D, Chua S, Lee C, Basquill C, Papana A, Theodoratou E, et al. Global and regional estimates of COPD prevalence: Systematic review and meta-analysis. J Glob Health. 2015;5(2)020415. https:// doi.org/10.7189/jogh.05.020415

3. Khakban A, Sin DD, FitzGerald JM, McManus BM, Ng R, Hollander $Z$, et al. The Projected Epidemic of Chronic Obstructive Pulmonary Disease Hospitalizations over the Next 15 Years. A Population-based Perspective. Am J Respir Crit Care Med. 2016;195(3):287-291.

4. Laniado-Laborín R. Smoking and chronic obstructive pulmonary disease (COPD). Parallel epidemics of the 21 st century. Int $J$ Environ Res Public Health. 2009;6(1):209-24. https://doi.org/10.3390/ ijerph6010209

5. European Lung White Book [homepage on the Internet]. Lausanne: European Respiratory Society; c2016 [cited 2016 Oct 1]. The burden of lung disease; [about 32 screens]. Available from: http://www. erswhitebook.org/chapters/the-burden-of-lung-disease/

6. Woodruff PG, Barr RG, Bleecker E, Christenson SA, Couper D, Curtis JL, et al. Clinical Significance of Symptoms in Smokers with Preserved Pulmonary Function. N Engl J Med. 2016;374(19):181121. https://doi.org/10.1056/NEJMoa1505971

7. Miravitlles M, de la Roza C, Naberan K, Lamban M, Gobartt E, Martin A. Use of spirometry and patterns of prescribing in COPD in primary care. Respir Med. 2007;101(8):1753-60. https://doi.org/10.1016/j. rmed.2007.02.019

8. Jamal A, Dube SR, Malarcher AM, Shaw L, Engstrom MC; Centers for Disease Control and Prevention (CDC). Tobacco use screening and counseling during physician office visits among adults-Nationa Ambulatory Medical Care Survey and National Health Interview Survey, United States, 2005-2009. MMWR Suppl. 2012;61(2):38-45.

9. Korzybski D, Bilska A, Skrzypczyńska E, Górecka D. Smoking habits among Polish pulmonary physicians [Article in Polish]. Pneumonol Alergol Pol. 2008;76(3):142-7.

10. Miller MR, Hankinson J, Brusasco V, Burgos F, Casaburi R, Coates A et al. Standardisation of spirometry. Eur Respir J. 2005;26(2):319-38. https://doi.org/10.1183/09031936.05.00034805

11. Hyatt RE, Scanlon PD, Nakamura M. Interpretation of pulmonary function tests: a practical guide. 4th ed. Philadelphia: Wolters Kluwer Health; 2014.

12. Global Initiative for Chronic Obstructive Lung Disease-GOLD [homepage on the Internet]. Bethesda: GOLD; c2016 [cited 2017 Mar 25]. GOLD 2017 Global Strategy for the Diagnosis, Management and Prevention of COPD; [about 2 screens]. Available from: http:// goldcopd.org/gold-2017-global-strategy-diagnosis-managementprevention-copd/

13. European COPD Coalition-ECC [homepage on the Internet]. Brussels: ECC; c2016 [cited 2016 Sep 15] Prevalence in EU; [about 3 screens]. Available from: http://www.copdcoalition.eu/about-copd/prevalence

14. Vandevoorde J, Verbanck S, Gijssels L, Schuermans D, Devroey D, De Backer J, et al. Early detection of COPD: a case finding study in general practice. Respir Med. 2007;101(3):525-30. https://doi. org/10.1016/j.rmed.2006.06.027

15. Konstantikaki V, Kostikas K, Minas M, Batavanis G, Daniil Z, Gourgoulianis $\mathrm{Kl}$, et al. Comparison of a network of primary care physicians and an open spirometry programme for COPD diagnosis. Respir Med. 2011;105(2):274-81. https://doi.org/10.1016/j. rmed.2010.06.020

16. Fukahori S, Matsuse $H$, Takamura $N$, Hirose $H$, Tsuchida T, Kawano $T$, et al. Prevalence of chronic obstructive pulmonary diseases in general clinics in terms of FEV1/FVC. Int J Clin Pract. 2009;63(2):269 74. https://doi.org/10.1111/j.1742-1241.2008.01873.x

17. Vukoja M, Rebić P, Lazić Z, Mitić Milikić M, Milenković B, Zvezdin B, et al. Early detection of asthma and chronic obstructive pulmonary disease in primary care patients. Med Pregl. 2013;66(1-2):46-52 https://doi.org/10.2298/MPNS1302046V

18. van Schayck CP, Chavannes NH. Detection of asthma and chronic obstructive pulmonary disease in primary care. Eur Respir J Suppl. 2003;39:16s-22s. https://doi.org/10.1183/09031936.03.00040403

19. Regan EA, Lynch DA, Curran-Everett D, Curtis JL, Austin JH, Grenier PA, et al. Clinical and Radiologic Disease in Smokers With Normal Spirometry. JAMA Intern Med. 2015:175(9):1539-49. https://doi. org/10.1001/jamainternmed.2015.2735

20. Tantucci C, Modina D. Lung function decline in COPD. Int J Chron Obstruct Pulmon Dis. 2012;7:95-9. https://doi.org/10.2147/COPD S27480

21. Mannino D, Buist A, Petty $T$, Enright $P$, Redd $S$. Lung function and mortality in the United States: data from the First National Health and Nutrition Examination Survey follow up study. Thorax. 2003;58(5): 388-93. https://doi.org/10.1136/thorax.58.5.388

22. Raherison C, Girodet PO. Epidemiology of COPD. Eur Respir Rev. 2009;18(114):213-21. https://doi.org/10.1183/09059180.00003609

23. National Institute for Health and Care Excellence-NICE [homepage on the Internet]. London: NICE; c2016 [cited 2016 Feb 26] Chronic obstructive pulmonary disease in over 16s: diagnosis and management; [about 4 screens]. Available from: https://www.nice. org.uk/guidance/cg101

24. Qaseem A, Wilt TJ, Weinberger SE, Hanania NA, Criner G, van der Molen $\mathrm{T}$, et al. Diagnosis and management of stable chronic obstructive pulmonary disease: a clinical practice guideline update from the American College of Physicians, American College of Chest Physicians, American Thoracic Society, and European Respiratory Society. Ann Intern Med. 2011;155(3):179-91. https:// doi.org/10.7326/0003-4819-155-3-201108020-00008

25. Lavinghouze SR, Malarcher A, Jama A, Neff L, Debrot K, Whalen L. Trends in Quit Attempts Among Adult Cigarette Smokers - United States, 2001-2013 MMWR Morb Mortal Wkly Rep. 2015;64(40):1129 35. https://doi.org/10.15585/mmwr.mm6440a1

26. Ilić D. Rezultati istraživanja zdravlja stanovništva Srbije, 2013. Godina Beograd: Službeni glasnik (SR); 2014. Report No.:978-86-7358-060-9.

27. Lindberg A, Bjerg A, Rönmark E, Larsson LG, Lundbäck B. Prevalence and underdiagnosis of COPD by disease severity and the attributable fraction of smoking Report from the Obstructive Lung Disease in Northern Sweden Studies. Respir Med. 2006;100(2):264-72. https:// doi.org/10.1016/j.rmed.2005.04.029

28. Čovinović Šternić N. Nacionalni vodič dobre kliničke prakse za dijagnostikovanje i lečenje hronične opstruktivne bolesti pluća Beograd: Republička stručna komisija za izradu i implementaciju vodiča dobre kliničke prakse, Ministarstvo zdravlja Republike Srbije (SR); 2013. Report No.:978-86-83607-85-3.

29. Roberts NJ, Patel IS, Partridge MR. The diagnosis of COPD in primary care; gender differences and the role of spirometry. Respir Med. 2016;111:60-3. https://doi.org/10.1016/j.rmed.2015.12.008

30. Jiménez-Ruiz C, Miravitlles M, Sobradillo V, Gabriel R, Viejo JL, Masa $\mathrm{JF}$, et al. Can cumulative tobacco consumption, FTND score, and carbon monoxide concentration in expired air be predictors of chronic obstructive pulmonary disease? Nicotine Tob Res. 2004;6(4):649-53. https://doi.org/10.1080/14622200410001727948

31. Agnew M. Ask the Expert: Lung function measurement. Breathe. 2009;5(3):224-6. https://doi.org/10.1183/18106838.0503.224

32. Frei A, Siebeling L, Wolters C, Held L, Muggensturm P, Strassmann $A$, et al. The Inaccuracy of Patient Recall for COPD Exacerbation Rate Estimation and Its Implications: Results from Centra Adjudication. Chest. 2016;150(4):860-868. https://doi.org/10.1016/j. chest.2016.06.031 